\title{
SOCIEDADES DE ECONOMIA MISTA E REFORMA ADMINISTRATIVA
}

\section{Diogo de FigueIREDO MOREIRA NETO}

\begin{abstract}
1. À guisa de introdução sobre as sociedades de economia mista $-2 . O$ regime geral privado das sociedades de economia mista e suas exceções constitucionais - 3. Uma exceção doutrinariamente proposta - 4. Privatização das sociedades de economia mista - 5. Breves conclusões
\end{abstract}

\section{1. À guisa de infrodução sobre as sociedades de economia mista}

Trata-se de um instituto que, ao mesmo tempo em que descentraliza e racionaliza atividades estatais, promove uma parceria entre capitais públicos e privados para o desempenho de empreendimentos mercantis, com ou sem delegação de competências administrativas específicas.

Dentre os três tipos básicos de descentralização de atividades administrativas, que são, a político-administrativa, a administrativa e a social, a primeira se opera pelo desdobramento de entidades políticas com assento constitucional; a segunda se realiza através de entidades administrativas que são criadas ou têm sua criação autorizada por lei; e a terceira se vale de instituições extraestatais, criadas pela própria sociedade. No caso das sociedades de economia mista, está-se diante do segundo modelo, o de descentralização administrativa.

Subjacente a essa classificação, em que se considera a origem substantiva da competência para o exercício de determinada atividade, está o conceito material que lastreia a distinção entre administração direta e indireta.

Já o conceito formal em que se baseia a distinção entre administração direta e indireta, se encontra positivado no Decreto-lei $n^{2} 200 / 67$, com a modificação introduzida pela Emenda Constitucional n 19/98, que acrescentou à categoria da administração indireta as empresas subsidiárias das empresas estatais, tal como deflui da nova redação do art. $173, \S 1^{\circ}$, da Constituição.

Além desses dois tipos explícitos, a administraf̧ão direta e a indireta, tornou-se implícita na Constituição uma terceira modalidade de prestação administrativa do 
Estado. a administração associada. já evidente nas múltiplas previsões, em seu texto. de variedades de descentralização social, como, genericamente, se encontra no art. $174 \S 20$. e, especificamente, exemplificadas no art. 194, VII; art. 195, § 70; art. 197; art. 199, § 1; art. 204, II; art. 209; art. 213; art. 217 e art. 218, § 49.

Todos esses dispositivos apontam no sentido da expansão das modalidades de descentralização social, bem como das correlatas atividades de fomento público, que o Poder Público deverá prover dando também preferência a operar através de transferências de atividades a entes intermédios de variada natureza.

O conceito legal das sociedade de economia mista se encontra no art. 50, III, do Decreto-lei no 200/67, com a redação que lhe deu o Decreto-lei ${ }^{0} 900 / 69$, caracterizado pelos seguintes elementos:

a) personalidade de direito privado;

b) criação por lei (autorização legal, segundo a Constituição, como no art. 236 da Lei das Sociedades Anônimas);

c) objeto ligado à exploração econômica;

d) forma de sociedade anônima;

e) controle majoritário da União ou de entidades da administração direta.

Quanto ao regime jurídico que as rege, a regra constitucional é clara: as sociedades de economia mista obedecem àquele instituído para as empresas privadas (art. $173, \S 19, \mathrm{CF})$, ressalvadas as exceçōes constitucionais.

Como corolário, são inadmissíveis exceções legais (como são, por exemplo, as do Capítulo XIX da Lei das Sociedades Anônimas), e, com maior razão, não devem ser acolhidas exceções doutrinárias, como a que adiante se exporá, apontando diferenças constitucionalmente inexistentes entre "tipos" de sociedade de economia mista, como justificativa para a ampliação aplicativa, a algumas delas, de regimes excepcionais.

2. O regime geral privado das sociedades de economia mista e suas excę̧̃es constitucionais

Provido que o regime geral das sociedades de economia mista é o "regime próprio das empresas privadas, inclusive quanto aos direitos e obrigações civis, comerciais, trabalhistas e tributários"(art. 173, $\S 1^{\underline{0}}$, II. CF), todas as exceções devem estar previstas na Constituição.

Distinguem-se, assim, três blocos de exceções constitucionais ao regime geral privado, ou seja, três distintos conjuntos de dispositivos, introdutores de regras de direito público que lhe são parcialmente derrogatórias, no que se refere às sociedades de economia mista: $1^{\circ}$ ) as exceções incidentes sobre sua constituição, $2^{\circ}$ ) as exceções referidas a seu funcionamento e $3^{\text {o}}$ ) as exceções atinentes à sua fiscalização.

12) Exceções ao regime de constituição

A mais importante exceção diz respeito à criação. As sociedades de economia mista não podem ser criadas livremente pela Administração, devendo ter sua instituição autorizada por lei específica (art. 37, XIX, CF). 
Ainda assim, com preocupação de caracterizar inequivocamente a presença do Estado nas atividades econômicas como excepcional (art. 173, caput, CF), o legislador constitucional, limita a proliferação dessas entidades exigindo que sua função social (art. 173, $\S 1^{2}, \mathrm{I}, \mathrm{CF}$ ) esteja previamente definida em estatuto jurídico a ser baixado por lei federal (art. 173, § 1ํㅡ. CF), aplicável também às duas outras modalidades de empresas estatais, ou seja, às empresas públicas e às subsidiárias de ambas.

O descumprimento de qualquer dessas restrições constitucionais, tanto a primeira, de natureza formal, quanto a segunda, de natureza material, desvalida sua criação.

A constituição e o funcionamento interno de seus órgãos societários, os conselhos de administração e fiscal, inclusive a participação dos acionistas minoritários, e os mandatos dos administradores serão estabelecidos nesse já referido estatuto jurídico a ser baixado por lei federal (art. 173, § $1^{\circ}$, IV e V, CF).

Finalmente, as sociedades de economia mista não poderão criar sua próprias subsidiárias, nem, tampouco, participar em empresa privada sem autorização legislativa colhida para cada caso (art. 37, XX, CF).

\section{Exceções ao regime de funcionamento}

No exercício de delegação legal de atividade estatal, vale dizer, agindo como executoras indiretas de funções de administração pública, as sociedades de economia mista ficam submetidas aos princípios reitores aplicáveis a essas atividades: legalidade, impessoalidade, moralidade, publicidade, eficiência (art. 37, caput, CF), bem como aos demais princípios dessumidos dos incisos e parágrafos pertinentes deste mesmo artigo.

Assim é que, excepcionalmente, os empregos em sociedades de economia mista devem ser acessiveis aos brasileiros que preencham os requisitos estabelecidos em lei, bem como aos estrangeiros, também na forma da lei (art. 37, I,CF); a investidura nesses empregos dependerá de aprovação prévia em concurso público de provas ou de provas e de títulos, de acordo com sua natureza e a complexidade (art. 37, II, CF); o prazo de validade desses concursos públicos será de até dois anos, prorrogável uma vez, por igual período (art. 37, III, CF), e durante esse prazo improrrogável, que deverá ser previsto no edital de convocação, os candidatos aprovados terão direito de preferência a serem contratados para os empregos a que concorreram (art. 37, IV, CF).

Ainda como exceção, as sociedades de economia mista, do mesmo modo que qualquer outra entidade da administração direta ou indireta, deverão reservar um percentual de empregos para as pessoas deficientes, definindo os critérios de sua admissão (art. 37, VIII, CF).

Quanto aos salários dos empregados das sociedades de economia mista, a eles se estende a proibição de acumulação remunerada, nos mesmos casos em que se a veda aos ocupantes de cargos públicos (art. 37, XVII, CF) e, também excepcionalmente, a eles se aplicará o teto remuneratório, previsto no art. $37, \mathrm{XI}, \mathrm{CF}$, sempre 
que essas entidades recebam recursos do Poder Público para pagamento de despesas de pessoal ou de custeio em geral, e apenas nessas hipóteses (art. 37, § 9², CF).

Outra exceção está no regime de licitações e contratações. As sociedades de economia mista foram nominadamente excluídas do alcance das normas gerais, de competência da União, previstas no art 22, XXVII, da Constituição e, em consequiência, do regime geral instituído pela Lei $\mathrm{n}^{0} 8.666 / 93$, mas o mesmo dispositivo constitucional, in fine, as sujeita a um específico regime para as suas licitações $e$ contratações, disposto no já referido estatuto jurídico (art. 173, § $1^{0}, \mathrm{III}$ ).

Por estarem submetidas a esse regime legal especial, excepcionalmente limitador da livre contratação, fica afastado não só o regime legal geral de licitações e contratações administrativas, fundado no art. $22, \mathrm{XVII}, \mathrm{CF}$, como também a sua aplicação subsidiária, pois nenhum regime público, pouco importa se geral ou especial, poderá ser aplicado para ampliar ou agravar uma estrita derrogação do regime próprio estabelecido no art. 173, § 1ํㅡ, II da Constituição.

Com efeito, esse novo regime especial, que foi previsto pela Emenda $n^{0} 19 / 98$ para reger as empresas estatais da administração indireta, veio a ser propositada e sensivelmente simplificado com a finalidade de aliviá-las dos encargos e dos ônus burocráticos, que lhes era impostos no regime constitucional originário.

Ponderável expressão dos comentaristas das normas licitatórias e de contratação administrativa já haviam reiteradamente observado a desproporcionalidade que resulta da indiscriminada extensão, às empresas do Estado, das regras de controle prévio impostas à sua burocracia, delas resultando o sacrifício de sua competitividade empresarial e o conseqüente encarecimento de seus produtos e serviços, fossem privados ou públicos.

Neste sentido, há um nítido avanço promovido pela reforma administrativa em curso, já que as regras do regime licitatório e de contratação a elas aplicáveis não deverão observar senão os princípios constitucionais gerais da administração pública, estabelecidos no art. 37, caput, CF.

Ainda assim, observe-se, os certames licitatórios e a disciplina contratual derrogatória do regime geral privado serão obrigatórios para as sociedades de economia mista apenas em quatro hipóteses de contratação: obras, serviços, compras e alienações (art. 173, 173, § 1ำ I).

É necessário, por fim, distinguirem-se as hipóteses em que quaisquer desses quatro tipos de contrato serão por elas celebrados como atividade meio, daquelas em que eles foram previstos nas respectivas leis autorizativas como a própria atividade fim da sociedade de economia mista, uma vez que, neste caso, estaria despida de sentido uma interpretação que as considerasse obrigadas a licitar obras, serviços, compras e alienações que se constituíssem em seu próprio objetivo social.

Finalmente, em confirmação de sua nova inserção concorrencial no mercado, ficou vedado às sociedades de economia mista gozarem de privilégios ficais não extensivos às empresas do setor privado (art. $173, \S 2^{\circ}$. CF), ou seja, a lei tanto não lhes pode agravar como, tampouco facilitar-lhes a livre competição: nec prodest, nec nocet. 
Concentra-se, contudo, na fiscalização dos resultados, o principal e mais amplo endereçamento do regime público sobre as atividades das sociedades de economia mista, uma ênfase que se coaduna com os modernos princípios da administração pública incorporados na Emenda $n^{\mathfrak{Q}} 19 / 98$, levando à substituição dos controles burocráticos de procedimento, praticados ante acta, por controle gerenciais de resultados, exercidos post acta.

Assim, além das modalidades de controle societárias, próprias a qualquer sociedade anônima, dispostas nas leis comerciais que as regem, essas entidades se submetem a vários regimes públicos de controle finalístico.

Desde logo, o estatuto jurídico, previsto no art. 173 , § 192 da Constituição, deverá instituir duas modalidades distintas de controle: uma, geral, prevendo formas de fiscalização pelo Estado e pela sociedade (inciso I), e outra, específica e interna, prevendo a avaliação de desempenho e a responsabilidade dos administradores (inciso $\mathrm{V}$ ) perante os órgãos estatais.

Quanto à fiscalização pela sociedade, a adoção de formas de participação do administrado é constitucionalmente obrigatória para qualquer entidade da administração direta ou indireta (art. $37, \S 3^{9}$ ), que, não podendo delas prescindir, deverá discipliná-las em lei.

Com efeito, a definição legal dos instrumentos de participação à disposição dos administrados não é uma faculdade dos legisladores mas uma obrigação a eles constitucionalmente imposta, de modo que, enquanto não forem editadas as respectivas leis, estar-se-á caracterizando uma gravíssima inconstitucionalidade material, em detrimento dos princípios democrático e da soberania popular e em frontal violação do art. $1^{\circ}$, parágrafo único, combinado com o referido art. $37, \S 3^{\circ}$, da Carta Magna.

A eles se acresce todo o sistema de controle fiscalizatório contábil, financeiro, orçamentário, operacional e patrimonial, estabelecido na Seção IX, do Capítulo I, do Título IV, da Constituição, por força da inclusão genérica, nesse sistema, das entidades de administração indireta (art. 70, caput, CF), destacando-se, a seguir, os dispositivos pertinentes.

Está previsto o julgamento de contas dos administradores e demais responsáveis por dinheiros, bens e valores públicos da administração indireta, o que inclui as sociedades de economia mista, e daqueles que derem causa a perda, extravio ou outra irregularidade de que resulte prejuízo ao erário público (art. 71, II, CF). Observe-se, todavia, que esta submissão está adscrita a recursos públicos geridos no âmbito das sociedades de economia mista.

No tocante ao controle de gastos com o pessoal, os atos referidos no art. 71, III, CF, admissão de pessoal, aposentadorias e pensões, estão sujeitos a registro, em que se lhes apreciará a legalidade.

Essa específica competência fiscalizadora cabe aos Tribunal de Contas da União, na órbita federal, e aos Tribunais de Contas dos Estados e do Distrito Federal, bem como aos Tribunais e Conselhos de Contas dos Municípios, nas demais unidades 
da Federação. como se dispõe no art. 75. caput. CF, que poderão exercer as atribuições discriminadas no art. 71, IV, CF.

A fiscalização de contas se estende, ainda, às sociedades de economia mista supranacionais de cujo capital social a União participe, de forma direta ou indireta, nos termos do tratado constitutivo (art. 7I, V, CF).

Finalmente, além dos três blocos examinados, existe uma exceção de direito público imposta diretamente aos ocupantes de empregos, em sociedades de economia mista, que lhes possibilitem o acesso a informações privilegiadas; nessa hipótese, a lei deverá dispor sobre os requisitos e restrições incidentes tanto sobre os empregados quanto sobre os que deixaram de sê-lo.

\section{Uma exceção doutrinariamente proposta}

Após a promulgação da Constituição de 1998, o ilustre jurista Hely Lopes

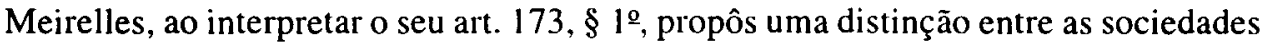
de economia mista que exercessem atividade econômica e as sociedades de economia mista prestadoras de serviços públicos'

Não lhe parecia razoável, à época, aplicar o regime jurídico da empresa privada às sociedades de economia mista prestadoras de serviços públicos, por receio de que isso as desgarrasse, ainda mais do que já então se encontravam, dos controles estatais, preocupando-se, o ilustre autor, não só com o bom gerenciamento dos vultosos recursos públicos nelas investidos, mas com a preservação de sua impessoalidade, uma vez que nelas se confundiam, à época, as competências executoras e reguladoras de serviços públicos.

Essa interpretação teve seguidores, o que se explica pela nomeada do doutrinador, mas, por inércia, acabou se mantendo, sem que se atentasse que, com a evolução juspolítica e as mutações do direito público durante o decênio, ela havia perdido sua únicas fundamentação teleológica razoável.

Com efeito, o que poderia parecer então vultosos aportes financeiros estatais, perdera sua expressão econômica, ante a crescente necessidade de incorporarem-se novas e custosas tecnologias à produção de bens e de serviços, muito além da capacidade impositiva do Estado para gerar capitais públicos

Por outro lado, as empresa do Estado tinham perdido a dupla competência decisória de que dispunham, a competência de execução da competência de regulação, cindida hoje claramente entre entes executores e entes reguladores, de modo que aquela "interpretação ampliativa dos controles" já a nada mais levava que ao absurdo de tornar a gestão dessas empresas estatais menos eficiente e mais cara do que a das empresas privadas concorrentes.

Tal interpretação impunha, por via interpretativa, ao Estado, custos majorados no cumprimento de rituais burocráticos; à sociedade, ônus acrescidos de arcar com o deficit de estatais ineficientes; e aos acionistas minoritários, um prejuízo injusto, 
quando se deveria. exatamente ao oposto, garantir a igualdade de condiçōes das empresas estatais perante o mercado, necessária para estabelecer-se uma sadia competição entre elas e suas congêneres privadas.

Com o advento da Emenda Constitucional no 11/98, o documento central da reforma administrativa que vem sendo empreendida neste final de década e de século, alterando e aclarando a redação do referido dispositivo, tornou-se evidente a mens legis, econômica e administrativa, o que dissipa qualquer dúvida que ainda pudesse remanescer a respeito da antiga interpretação, ainda perpassada de uma certa anacrônica reminiscência estatista. Essa definição aclarativa, a registramos em nossos Apontamentos sobre a Reforma Administrativa ${ }^{2}$.

Mas o descabimento dessa distinção, mesmo no tempo em que esteve em vigor a redação revogada, do art. $173, \S 1^{\circledR}$, da Constituição de 1988 , já bem se havia patenteado para os comercialistas, como se pode ler em José Edwaldo Tavares Borba ${ }^{3}$.

Para melhor compreender os argumentos do ilustre comercialista, vale recordar o dispositivo constitucional examinado em sua redação original, que ensejaria a pretendida distinção:

“Art.173.

$\S 1^{2}-\mathrm{A}$ empresa pública, a sociedade de economia mista e outras entidades que explorem atividade econômica sujeitam-se ao regime jurídico próprio das empresas privadas, inclusive quanto às obrigações trabalhistas e tributárias."

José Edwaldo Tavares Borba apresenta-nos dois fundamentos interpretativos: o gramatical e o lógico-sistemático, cabendo acrescentar, como também se o fará, o argumento teleológico.

O argumento gramatical é apresentado, com a habitual precisão desse autor, em sua monografia referida. permitindo-nos selecionar os excertos mais incisivos.

"A questão se resume em elucidar se a expressão "que explorem atividade econômica" refere-se apenas a 'outras entidades', ou se abrangeria igualmente as sociedades de economia mista e as empresas públicas. Em outras palavras. Existiriam duas categorias de sociedades de economia mista e empresas públicas? De um lado as que exploram atividade econômica, e portanto sujeitas à legislação privada e, de outro, as que não exploram atividade econômica mas, em vez disso, serviços públi$\cos , e$ que assim estariam submetidas ao direito público?

Se começarmos pela interpretação gramatical, veremos que a oração adjetiva 'que explorem atividade econômica' é uma oração adjetiva restritiva, tanto que não se encontra entre vírgulas, vinculando-se ao seu antecedente 'outras entidades', cujo

2 Rio de Janeiro, Ed. Renovar, 1999, pp. 114 e 115

3 JOSÉ EDWALDO TAVARES BORBA, Direito Societário Rio de Janeiro, Livraria Editora Freitas Bastos, $4^{2}$ ed., 1998, e, de modo especial, particularizado em Sociedade de Economia Mista e Privatização, Rio de Janeiro, Ed. Lumen Juris, 1997, com as citaçōes transcritas adiante, das páginas 95, 96 e 97 
sentido completa e integra. Se a expressão 'que explorem atividade econômica' guardasse vinculação aos demais termos que compõem o sujeito da oração principal seria uma oração adjetiva explicativa, posto que estaria a lhes acrescentar uma qualidade acessória, e, nesse caso, deveria estar entre vírgulas.

Convém, nesse particular, recorrer a Celso Cunha (Nova Gramática do Português Contemporâneo $-2^{a}$ edição, págs. 588/589), que assim comenta as orações adjetivas:

'As restritivas, como o nome indica, restringem. limitam, precisam a significação do substantivo (ou pronome) antecedente. São, por conseguinte, indispensáveis ao sentido da frase; e, como se ligam ao antecedente sem pausa, dele não se separam, na escrita, por vírgula. Exemplos: 'És um dos raros homens que têm o mundo nas mãos' (A. Abelaira, NL, 121).

As explicativas acrescentam ao antecedente uma qualidade acessória, isto é, esclarecem melhor a sua significação, à semelhança de um aposto. Mas, por isso mesmo, não são indispensáveis ao sentido essencial da frase. Na fala, separam-se do antecedente por uma pausa, indicada na escrita por vírgula: 'Tio Cosme, que era advogado, confiava-lhe a cópia de papéis de autos' (Machado de Assis, OC, 1, 734)."

E acrescenta, José Edwaldo Tavares Borba, o argumento lógico-sistemático:

"A interpretação lógico-sistemática confirma a interpretação gramatical, uma vez que a sociedade de economia mista e a empresa pública encontram-se legalmente conceituadas como entidades criadas 'por lei para a exploração de atividade econômica' (art. 5o, incisos II e III, do Decreto-lei no 200/67, com a redação decorrente do Decreto-lei $\mathrm{n}^{\mathrm{9}}$ 900/69).

Assim, a Constituição Federal (art. 173, $\S 1^{2}$ ), ao fazer alusão à sociedade de economia mista e à empresa pública, estava contemplando entidades cuja natureza já lhes determinava a sua condição de entes voltados para a atividade econômica. $O$ art. $173, \S 1^{2}$, em um esforço de generalização. faz referência ainda a 'outras entidades', estas sim dependentes de qualificação pela característica da exploração de atividade econômica. E nesse âmbito das 'outras entidades', poderíamos situar toda e qualquer sociedade comercial ou civil sob o controle do poder público.

As sociedades de economia mista e empresas públicas destinam-se, pois, necessariamente, ao exercício da atividade econômica. E não poderia ser diferente, pois, revestindo a forma de sociedade comercial, daí decorre, como um corolário, o caráter mercantil das atividades desenvolvidas, e bem assim a finalidade lucrativa, que é inerente à mercancia.

As atividades típicas de administração pública deverão ser exercidas pela administração centralizada ou por autarquias, e, em certas circunstâncias, por fundações públicas, jamais por sociedades comerciais.

Isto não significa que os serviços públicos não possam ser concedidos a sociedades de economia mista ou a empresas públicas, como de resto podem ser concedidos a qualquer empresa privada.

As concessionárias privadas de serviços públicos não deixam, por força da concessão, de exercer uma atividade econômica. $O$ serviço público, quando concedido, não deixa, igualmente, de ser um serviço público, mas a concessionária, ao 
explorá-lo. explora-o com finalidade de lucro, exercendo, portanto, uma atividade econômica.

O governo, ao constituir uma sociedade de economia mista ou uma empresa pública para explorar um serviço público, escolhe uma forma privada de atuação, que tem na exploração da atividade econômica a condição de sua realização. Cabe, pois, afirmar que todas as sociedades de economia mista se destinam ao exercício de atividade econômica".

E. com a vênia do autor, pode-se aduzir, pelas mesmas razões, que o governo. ao eleger a forma privada e mercantil para atuar, fá-lo nas mesmas condições que qualquer outro empresário, ou seja, assume a álea do mercado. Tanto assim é, que recruta sócios privados para integrar um capital que deixa de ser público para ser misto, prevalecendo as regras de mercado e, por isso, não tem cabimento qualquer constrição de qualquer natureza oposta à sua gestão, que não aquelas que a própria Constituição expressamente haja imposto.

Mas José Edwaldo Tavares Borba ainda toca, en passant, no argumento, quiçá o mais importante, o teleológico, na seguinte frase:

“Com o fim de preservar a coerência de sistema, evitando que a legislação ordinária excepcionasse a legislaçäo comum das sociedades comerciais e estabelecesse privilégios ou restriçōes para as empresas do governo, determinou a Constituição Federal (art. 173, $§ 1^{\circ}$ ) que estas se sujeitassem ao regime jurídico próprio das empresas privadas, inclusive quanto às obrigações trabalhistas e tributárias." (n/ grifo).

Depreende-se de todo o exposto, que a Constituição não só impede que a lei possa beneficiar as sociedades de economia mista em detrimento das entidades privadas, como, ao revés, embora visando ao mesmo propósito, que é o de preservar a sadia competição no mercado (art. 170 , IV e $173, \S 4^{\circ}, \mathrm{CF}$ ), veda que as leis as possam prejudicar, com a imposição de controles burocráticos que as estorve em sua atuação no mercado.

Afinal, se considerados meramente os aportes de capital público às sociedades de economia mista, serão sobejamente suficientes os controles de resultado societários, a que se acrescem os controles finaceiro-orçamentários a cargo dos Tribunais de Contas e órgãos assemelhados, para se verificar a boa ou má gerência da sociedade de economia mista.

Esses controles financeiros, patrimoniais e até de economicidade de gestão, independem da sobreposição, sempre que houver delegação de serviços públicos, de outros controles administrativos próprios que recaem especificamente sobre a execução dessas atividades delegadas.

$\mathrm{O}$ que o legislador constitucional pretendeu, desde a redação original do art. $173, \S 1^{\circ}$, foi garantir a igualdade de competição no mercado de todas sociedades de economia mista, indistintamente, com o reconhecimento implícito de que a álea inafastável da mercancia seria um risco assumido pelo capital público a elas aportado, não tendo sentido impor-lhes um oneroso controle burocrático de procedimentos de gestão, mas, tão-somente, o controle societário de resultados, comum a todas as sociedades anônimas. 
Assim, valha mais este argumento de reforço, em se tratando de uma prestação empresarial de serviços públicos executada por sociedades de economia mista, não teria sentido adotar-se uma interpretação de que resultasse pô-las em desvantagem no mercado, até mesmo quando em cotejo ou competição com outras sociedades anônimas do setor privado também concessionárias e permissionárias de serviço público, até mesmo porque o custo acrescido aos serviços sempre será, de alguma maneira, repassado à sociedade, que o pagará, como um todo, através de impostos, ou, segmentadamente, através de tarifas.

$\mathrm{O}$ art $173, \S 1^{\circ}$, preserva, assim, o princípio constitucional da livre concorrência, ao garantir, sem exceção, a todas as sociedades de economia mista, a "sujeição ao regime jurídico próprio das empresas privadas".

Por derradeiro, ainda no campo da interpretação teleológica, se o que se pretende, afinal, são serviços públicos módicos, há que, necessariamente, pensar-se em eficiência, hoje também guindada a princípio constitucional da administração pública (art. 37, caput).

Ora, como esse desiderato só se alcança em ambiente de livre concorrência, em justa igualdade de condições, tornar-se-ia uma grosseira contradição sujeitar-se o investimento do Estado, feito nas sociedades de economia mista, a condições mais gravosas e a onerosos controles burocráticos de procedimentos de que, paradoxalmente, quaisquer concessionárias de serviços públicos estariam dispensadas.

Reitere-se, por derradeiro, que a polêmica chegou a seu fim com a nova redação do art. 173, § 1², da Constituição ${ }^{4}$.

\section{Privatização das sociedades de economia mista}

O conceito doutrinário (material) de privatização se assenta na premissa de que só se devem ser atividades estatais aquelas que lhe são essenciais e próprias, para evitar o agigantamento da máquina administrativa do Estado ou a dispersão de esforços, devolvendo, para tanto, à sociedade, atividades secundárias, econômicas ou sociais, a ele indevidamente atribuídas segundo este critério.

Em síntese, o que se objetiva é promover a reversão do imemorial fenômeno cratológico de concentração de poder, invariavelmente observado em qualquer campo de atividade, em qualquer tempo, em qualquer lugar e em qualquer pólo de concentração, sendo, porém, mais singularmente significativo e preocupante, quando se trata de uma organização estatal.

O conceito legal (formal) se expressa no inciso I, do art. $1^{2}$, da Lei $n^{2} 9.491$, de 9 de setembro de 1997, que redefiniu o Programa Nacional de Desestatização, como a reordenação da posição estratégica do Estado na economia, transferindo à iniciativa privada atividades consideradas como indevidamente exploradas pelo setor público. 
Observe-se que o conceito legal é mais restritivo. ao limitar o processo de privatização ao campo econômico, embora, adiante, o dispositivo legal coincida na premissa mais ampla da necessidade de concentração de esforços do Estado nas atividades em que sua presença seja fundamental para a consecução das "prioridades nacionais", introduzindo-se, portanto, um conceito jurídico indeterminado bem mais amplo. cuja definição concreta foi transferida à Administração Pública.

Estabelecer quais as atividades a serem privatizadas e quais os regimes jurídicos da privatização, são ambas decisões incluídas na reserva político-administrativa das entidade da Federação (art. 18, CF), só encontrando limites e condicionamentos na própria Constituição.

$\mathrm{Na}$ União, o regime ficou definido no art. $4^{2}$ da Lei $\mathrm{n}^{\circ} 9.491$, de 9 de setembro de 1997, que arrola as seguintes modalidades:

I alienação de participação societária, inclusive de controle acionário, preferentemente mediante pulverização de ações;

II abertura de capital;

III aumento de capital, com renúncia ou cessão, total ou parcial, de direitos de subscrição;

IV alienação, arrendamento, locação, comodato ou cessão de bens e instalações;

V dissolução de sociedades ou desativação parcial de seus empreendimentos, com a conseqüente alienação de seus ativos;

VI concessão, permissão ou autorização de serviços públicos.

Todas essas modalidades se resumem a três tipos: a transferência total; a transferência parcial e a extinção da atividade.

Observe-se, todavia, que quando se trata da privatização de serviço público, transfere-se a execu̧̧ão, permanecendo no Estado o controle administrativo, como uma atividade estatal de que não se pode demitir o Poder Público, ainda que perca o controle societário.

A transferência do controle acionário de uma sociedade de economia mista em nada altera a integridade patrimonial da empresa, não só se mantendo aquele fisicamente considerado, como também o patrimônio abstratamente considerado, ou seja, o status de delegatária de serviço público, o que inclui, em contrapartida, a submissão a todas as prerrogativas legais próprias do respectivo Poder Concedente, enquanto vigente a respectiva delegação, no decurso do chamado "prazo fixado no ato de outorga", referido no art. 42 da Lei 8.897/95.

Trata-se de investigar $o$ que se privatiza. Por certo e necessariamente, no caso de uma sociedade de economia mista, tanto a propriedade das ações pertencentes ao Estado, como, eventualmente, em caso de delegação, um serviço público que the tenha sido outorgado pela respectiva lei pré-instituidora.

Quanto à propriedade das ações, ela se transfere pela privatização segundo as formas previstas na Lei das Sociedades Anônimas, inclusive quanto ao controle acionário.

Quanto à titularidade da execução do serviço público, ela não se transfere pela privatização, pois continua a pertencer à sociedade anônima e não a seus antigos acionistas. 
Destarte. apenas à guisa de esclarecimento. não se aplica à hipótese o art. 27 da Lei $\mathrm{n}^{\mathrm{o}} 8.987 / 95$, pois esse dispositivo pressuporia:

1. a transferência de concessão ou

2. a transferência de controle societário de concessionária.

Ora. nem existe concessão contratada, nem, tampouco, a sociedade de economia mista é uma concessionária. A concessão é uma modalidade de delegação contratual e, em se tratando de sociedade de economia mista, a competência para prestar um serviço público não the foi transferida por contrato. mas por uma delegação legal, ou seja, ela foi outorgada diretamente à empresa estatal por vontade do legislador.

Ao anuir, através de lei de iniciativa do Poder Executivo, que a empresa estatal assumisse o correspondente risco de inercado, inerente à atividade empresarial, o legislador implicitamente autorizou que se incorporasse, como asset, a seu patrimônio, a delegação de serviço público, que justificaria, assim, a própria criação da sociedade.

Em consequiência, nenhuma das hipóteses daquele dispositivo tem aplicação, nem mesmo a segunda, pois a exigida "anuência do poder concedente" (pessoa jurídica de direito público) para transformar em delegação administrativa o que era originalmente uma delegação legal, já se encontra expressa na própria lei que autoriza a privatização, anuência essa que será sempre redundantemente secundada por uma reafirmação de vontade estatal em sede executiva, através do ato decisório da Administração que efetivamente licitará, pelo processo próprio das sociedades anônimas, a alienação acionária autorizada.

Assim, uma vez operada a privatização, a ex-sociedade de economia mista, que executava, por delegação legal, certo serviço público, continuará a prestá-lo, como entidade do setor privado, sob as mesmas condições e até o final do prazo originariamente previsto.

\section{Breves conclusões}

Ao que tudo indica, a paraestatalidade econômica, tal como intensamente praticada no Estado do Bem-Estar Social, ao ponto de ser um de seus símbolos, na figura do Estado-empresário, parece já se ter esgotado.

Por um lado, no que toca aos serviços públicos, não sendo mais possível aos Estados contemporâneos disporem de grandes somas de capital para instituir e manter empresas estatais, mesmo em sociedade com capitais privados, as soluções de transferência, como as concessionais, permissionais e assemelhadas se vão tornando as melhores opções, recolhendo-se, o Estado, às funções reguladoras e fiscalizadoras que lhe são próprias e inalienáveis.

Por outro lado, no que toca às chamadas atividades econômicas pioneiras, que seriam as instituídas para desenvolver certos setores produtivos, tampouco se justifica hoje derivar para elas recursos públicos cada vez mais escassos e necessários em atividades estatais essenciais, como o são a segurança a educação e a saúde públicas. 
Isso, com muito mais razão. quando o Estado tem condições de. sem sacrificálas, atuar bem mais efetivamente com adequadas políticas de fomento público $\mathrm{e}$ através de agências de desenvolvimento, manejando instrumentos de estímulo administrativos e de incentivos tributários, incomparavelmente menos dispendiosos e vantajosamente desburocratizados.

Restam, do elenco de possibilidades de utilização das sociedades de economia mista, aqueles especialíssimos casos em que sua criação vise a atender aos "imperativos da segurança nacional", na fórmula do art. 173, caput. CF.

Também aqui, na medida em que estão sendo revistos e redefinidos, como ocorre celeremente em nosso dias, os conceitos estratégicos que estiveram vigentes neste século que expira, e, em consequiência, variando o que hoje e amanhã se deva entender como "imperativos da segurança nacional", as prioridades de investimento obviamente mudarão também e, com elas, as futuras necessidades de manter, de criar ou de extinguir empresas estatais.

Assim posto, o futuro institucional das sociedades de economia mista não parece ser muito promissor e a sobrevida das existentes muito dependerá de como elas venham a se valer do desafogo burocrático e dos novos caminhos cooperativos e colaborativos que lhes proporcionam as novas regras constitucionais e se provem não apenas úteis como eficientes. 


\section{A Teoria Geral do Direito e o Marxismo}

E. B. Pasukanis

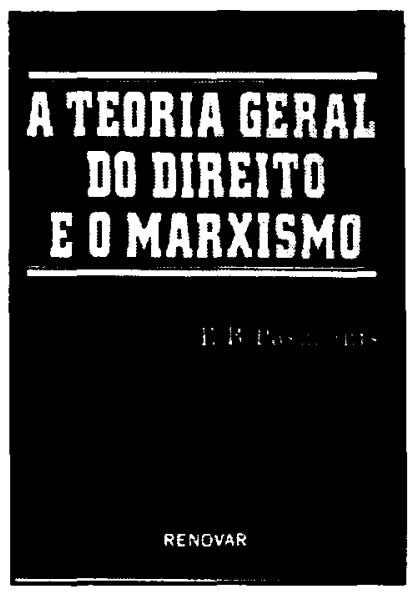

Neste livro, o autor examina, com o indispensável olhar crítico, alguns dos momentos mais densamente significativos dessa história, tal como ela se refletiu nas cartas constitucionais.

Ref. 131

Form. 14x21
Brochura 1997
Ref. 0015

Form. 14x21
Obra indispensável para todos que pensam o Direito de forma crítica e democrática. $O$ autor realiza sua investigação partindo do pressuposto de que o Direito é uma forma necessária da sociedade capitalista e que surge em conseqüência de determinado nivel de desenvolvimento das forças produtivas e das relações daí decorrentes. Este livro reveste-se de real importância aos estudiosos do Direito, que terão em mãos um instrumento capaz de propiciar aos setores democráticos da sociedade uma nova visão do fenômeno jurídico.
Brochura 1989
378 págs.

\section{Cartas Constitucionais Império, República \& Autoritarismo (Ensaio, Crítica e Documentação)}

Marcello Cerqueira

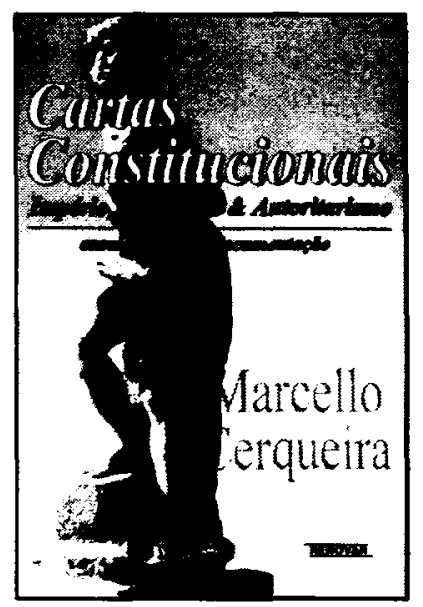

